CARDIOVASCULAR MEDICINE

\title{
Sinus node revisited in the era of electroanatomical mapping and catheter ablation
}

\author{
D Sánchez-Quintana, J A Cabrera, J Farré, V Climent, R H Anderson, S Y Ho
}

Heart 2005;91:189-194. doi: 10.1136/hrt.2003.031542

See end of article for authors' affiliations

.....................

Correspondence to: Dr Siew Yen Ho, National Heart and Lung Institute, Imperial College, Dovehouse Street, London SW3 6LY, UK; yen.ho@ imperial.ac.uk

Accepted 2 April 2004

\begin{abstract}
Objective: To study the architecture of the human sinus node to facilitate understanding of mapping and ablative procedures in its vicinity.

Methods: The sinoatrial region was examined in 47 randomly selected adult human hearts by histological analysis and scanning electron microscopy.

Results: The sinus node, crescent-like in shape, and 13.5 (2.5) mm long, was not insulated by a sheath of fibrous tissue. Its margins were irregular, with multiple radiations interdigitating with ordinary atrial myocardium. The distances from the node to endocardium and epicardium were variable. In $72 \%$ of the hearts, the whole nodal body was subepicardial and in 13 specimens $(28 \%)$ the inner aspect of the nodal body was subendocardial. The nodal body cranial to the sinus nodal artery was more subendocardial than the remaining nodal portion, which was separated from the endocardium by the terminal crest. In $50 \%$ of hearts, the most caudal boundaries of the body of the node were at least $3.5 \mathrm{~mm}$ from the endocardium. When the terminal crest was $>7 \mathrm{~mm}$ thick (13 hearts, $28 \%$ ), the tail was subepicardial or intramyocardial and at least $3 \mathrm{~mm}$ from the endocardium.

Conclusions: The length of the node, the absence of an insulating sheath, the presence of nodal radiations, and caudal fragments offer a potential for multiple breakthroughs of the nodal wavefront. The very extensive location of the nodal tissue, the cooling effect of the nodal artery, and the interposing thick terminal crest caudal to this artery have implications for nodal ablation or modification with endocardial catheter techniques.
\end{abstract}

B oth inappropriate sinus tachycardia (IST) and sinus nodal re-entrant tachycardia (SNRT) are arrhythmias arising from the sinoatrial area. Whereas re-entry in SNRT probably involves the sinus node or atrial tissue adjacent to the node, the mechanism of IST is poorly understood. Increased automaticity or a primary autonomic disturbance has been suggested as a possible mechanism. SNRT can be treated effectively and safely with radiofrequency catheter techniques, ${ }^{2}$ but ablation of IST is associated with poor long term success rates. ${ }^{3}{ }^{4}$ Even with three dimensional electroanatomical mapping, IST recurred in $21 \%$ of patients. ${ }^{5}$ This high recurrence rate may be due to autonomically related shifts in the site of impulse formation at the time of ablation but there may also be anatomical reasons preventing the ablation of the required mass of nodal tissues by an endocardial approach. ${ }^{5-10}$ Evidence of transmural and epicardial damage with intracardiac echocardiography has been suggested to indicate safe and effective ablation of IST. ${ }^{11}$ Since Keith and Flack ${ }^{12}$ first discovered the existence of the sinus node, several studies have described its location, morphology, size, and blood supply. ${ }^{13-19}$ None of these studies, however, has focused on providing the information needed to understand mapping and ablative procedures in patients with tachycardias arising from the sinoatrial region.

\section{METHODS}

We examined 47 randomly selected human heart specimens from archives in Spain and Portugal. These hearts were studied in accordance with local guidelines and ethics for research. No clinical information was available. The causes of death were recorded as traffic accident (12), liver cirrhosis or carcinoma (six), cerebral haemorrhage (six), suicide (six), pulmonary thromboembolism (four), food or gas poisoning (four), gun shot (two), drowning (two), meningitis (two), pneumonia (one), amyloid polyneuropathy (one), and dilated cardiomyopathy (one). They were from 31 men and 16 women aged $42(20)$ years, ranging from $20-80$ years. The hearts weighed 379 (32) g with a range of 352-500 g. We removed the sinoatrial junctional areas from each heart. Blocks were $2-3 \mathrm{~cm}$ long, included a short portion of the superior caval vein together with the terminal crest, and extended to the entrance of the inferior caval vein (fig l). Each block was then divided perpendicular to the terminal groove into transmural strips $2-3 \mathrm{~mm}$ wide. We processed 6-7 strips from each heart for embedding in paraffin wax separately. Strips were sectioned serially at $10 \mu \mathrm{m}$ thickness but every 100th section was cut at $14 \mu \mathrm{m}$. Every 20th section was stained with Masson trichrome. In keeping with previous studies, ${ }^{12}$ we describe the most superior part of the node as the "head", the middle part as the "body", and the inferior portion as the "tail" (fig l).

We noted the height and width of the sinus node in each section (fig 1) and calculated the total length of the node by counting the number of sections containing nodal tissue (table 1). We measured the maximum thickness of the terminal crest from epicardium to endocardium at the different parts of the sinus node, and the minimum and maximum distances from nodal tissue to epicardium and endocardium. Measurements were made under the microscope with the SigmaScan/Image program. At the nodal body, we measured the distance from the most caudal boundaries of the node to the endocardium (table 2). For scanning electron microscopy (Jeol JSM 5600), we deparaffinised the $14 \mu \mathrm{m}$ sections in xylene for 30 minutes and sputter coated the dried sections with gold (fig $2 \mathrm{~B}, \mathrm{G}, \mathrm{H}$ ).

Abbreviations: IST, inappropriate sinus tachycardia; SNRT, sinus nodal re-entrant tachycardia 


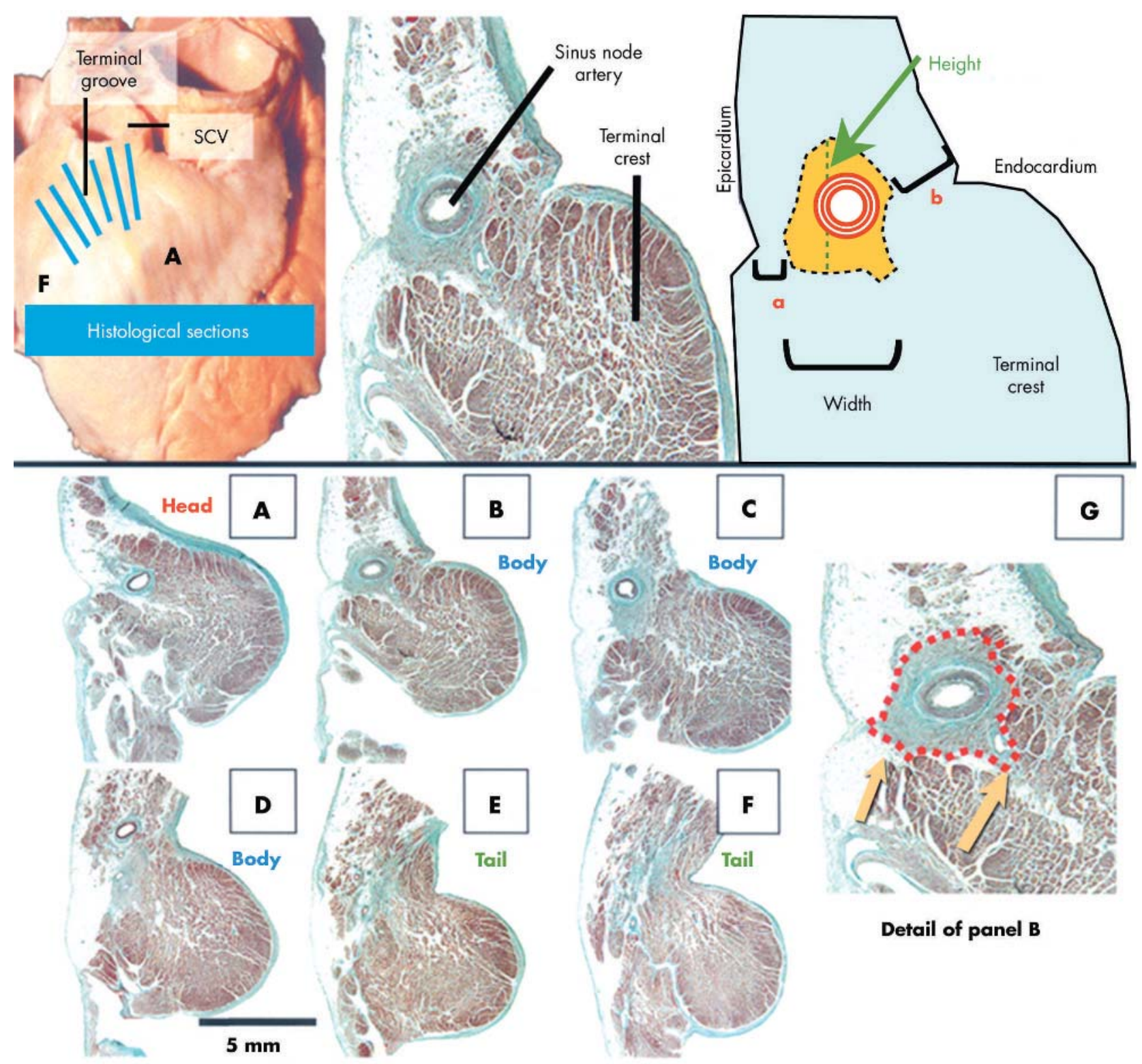

Figure 1 (Top) Gross specimen and example of a histological section accompanied by a diagram indicating the measurements made. (Bottom) Histological sections (Masson trichrome stain) taken through the levels A-F indicated on the gross specimen. (G) The red dotted line delineates the nodal boundaries. Note the irregular contour of the node and the extensions towards the neighbouring myocardium (arrows). Width and height of the node, and distances of nodal tissue to epicardium (a) and endocardium (b) were measured. SCV, superior caval vein.

\section{Statistical study}

Results are expressed as mean (SD). Quantitative data were compared by Student's unpaired $t$ test. Correlations between quantitative variables were analysed by linear regression analysis. A p value $<0.05$ was considered to be significant.

\section{RESULTS}

Nodal shape and dimensions

Although we observed many variations in the shape of the sinus node in our series, its morphology is crescent-like rather than fusiform or horseshoe as described in previous

\begin{tabular}{|c|c|c|c|c|c|c|c|c|}
\hline & \multicolumn{2}{|c|}{ Sinus node length $(\mathrm{mm})$} & \multicolumn{2}{|c|}{ Sinus node height $(\mathrm{mm})$} & \multicolumn{2}{|c|}{ Sinus node width (mm) } & \multicolumn{2}{|c|}{ Terminal crest thickness $(\mathrm{mm})$} \\
\hline & Mean (SD) & Range & Mean (SD) & Range & Mean (SD) & Range & Mean (SD) & Range \\
\hline Head & $2.2(1.2)$ & $1-4$ & $2.4(0.7)$ & $1-3.5$ & $1.2(0.3)$ & $0.5-2.2$ & $6.2(1.5)$ & $3-10$ \\
\hline Body & $9.5(2.3)$ & $6-14$ & $5.3(1.5)$ & $2.2-8.3$ & $1.5(0.5)$ & $0.5-3.5$ & $5.6(1.4)$ & $3-9$ \\
\hline Tail & $1.6(0.5)$ & $1-3.5$ & $1.1(0.2)$ & $0.4-1.5$ & $0.4(0.1)$ & $0.1-0.9$ & $4.2(1.2)$ & $2-8$ \\
\hline
\end{tabular}


Table 2 Distances between parts of the sinus node and the epicardium and endocardium of the terminal crest

\begin{tabular}{|c|c|c|c|c|c|c|c|c|}
\hline & \multicolumn{4}{|c|}{ Epicardial distances (mm) } & \multicolumn{4}{|c|}{ Endocardial distances (mm) } \\
\hline & Minimum & Range & Maximum & Range & Minimum & Range & Maximum & Range \\
\hline Head & $1.5(0.6)$ & $0.5-5$ & $2.5(0.5)$ & $2.0-5.1$ & $2.3(1.2)$ & $1-4.6$ & $3.1(1.1)$ & $2-5.2$ \\
\hline Body & $0.4(0.2)$ & $0.1-2.5$ & $1.5(0.4)$ & $1.0-3.5$ & $3.1(0.5)$ & $0-4.8$ & $3.9(0.4)$ & $3.5-5.3$ \\
\hline CBN & $0.3(0.1)$ & $0.1-2.1$ & $1.4(0.2)$ & $1.1-3.1$ & $4.2(0.4)$ & $2.3-4.6$ & $4.8(0.5)$ & $3.3-5.3$ \\
\hline Tail & $2.2(0.5)$ & $1-3.4$ & $3.1(0.3)$ & $2.5-4.1$ & $1.8(0.5)$ & $0-5.6$ & $3.9(0.5)$ & $3.3-5.8$ \\
\hline
\end{tabular}

studies. $^{101516}$ The long axis of the nodal body is parallel to the terminal groove, with the head and tail penetrating intramyocardially towards the subendocardium. Table 1 lists the length, height, and width of the head, body, and tail. The mean (SD) nodal length was 13.5 (2.5) mm (range 8$21.5 \mathrm{~mm}$ ). There was no correlation between size of the node and weight of the heart, size of the atrium, or thickness of the terminal crest. In 31 specimens $(66 \%)$ the height of the nodal body and tail was at least twice that of its width (fig $1 \mathrm{C}$, fig $2 \mathrm{~A}-\mathrm{E}$, fig $3 \mathrm{~A}$ ). At the nodal head, the height and width of the nodal tissue were similar. In the remaining 16 specimens (34\%), the width of the head was greater than its height.

\section{Histological examination}

The nodal cells, packed within a dense matrix of connective tissue, were arranged as interlacing strands of myocytes smaller and paler than working atrial myocardial fibres (figs 1-4). At the periphery of the node in $85 \%$ of the specimens (40 hearts), specialised nodal cells intermingled with ordinary atrial myocytes, without a discrete fibrous

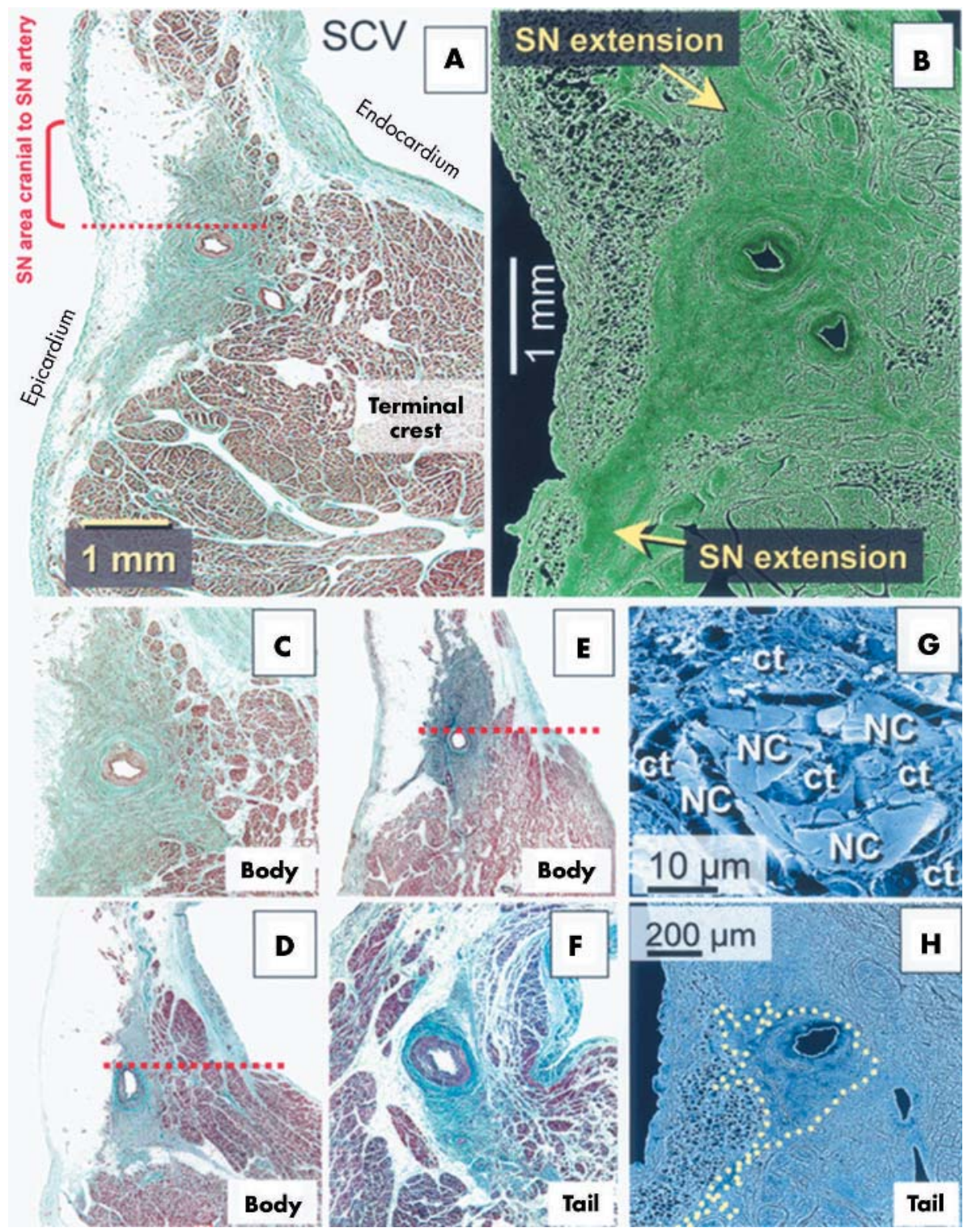

Figure 2 (A) Histological section of the nodal body (Masson trichrome stain). $\mathrm{SN}$, sinus node. (B) Scanning electron micrograph of the nodal body. The nodal mass cranial to the nodal artery is relatively close to the endocardium. Portions of the node caudal to the artery are separated from the endocardium by the thick terminal crest. Cranial and caudal extensions of the node are also present in this specimen. (C, D, E) Histological sections from three hearts illustrating the variable morphology of the nodal body and its extensions. In C and $\mathrm{E}$, the nodal artery is central; the vessel is eccentric in D. (F) Sample from a nodal tail where the artery occupies an eccentric position. The nodal mass superior to the sinus node artery (dotted red line in $D$ and $E$ ) is relatively subendocardial. (G, H) Scanning electron micrographs. $G$ shows small nodal cells (NC) tightly packed within a dense matrix of connective tissue (ct). $\mathrm{H}$ is from a nodal tail (yellow dotted line) and shows extensions as well as an eccentric position of the nodal artery. 

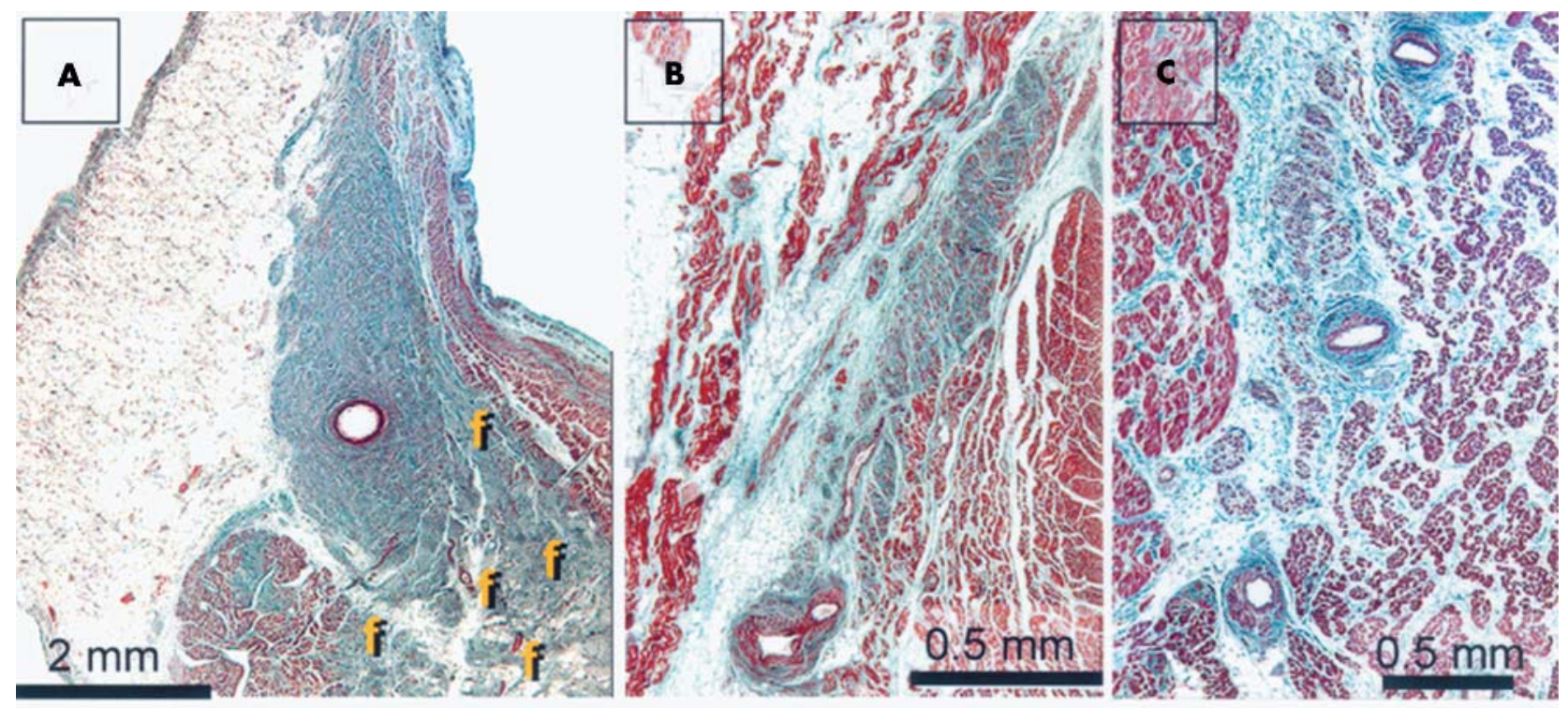

Figure 3 (A) Fibro-fatty tissue (f) between the caudal aspect of the nodal body and the subendocardium. (B, C) Fragmentation of the nodal tail into clusters. Masson trichrome stain.

border (fig 1G, fig 2C-F). Moreover, in 35 hearts (74\%) we observed short digitations of nodal tissue from the head, body, and tail penetrating the working atrial myocardium (fig $1 G$, fig 2). Each node had 1-10 radiations, from $0.2-$ $2 \mathrm{~mm}$ long, extending towards the superior caval vein (12 hearts; fig 2B, fig 4C,D,E), the subepicardium (30 hearts; fig $2 \mathrm{~A}, \mathrm{~B})$, and the terminal crest or the intercaval region (24 hearts; fig $1 G$, fig 4C,D,E). Most of these extensions stemmed from the body region where, in 28 of the 35 hearts with such extensions, we observed 5-8 radiations.

Histological examination with light and scanning electron microscopy showed that, in 30 specimens $(64 \%)$, the most distal area of the nodal tail $(<3 \mathrm{~mm})$ lost its compactness, breaking up into clusters of specialised myocytes that intermingled with fibro-fatty tissue and ordinary working myocytes in the subendocardium (fig 3B,C). Fragmentation of the nodal tail was unrelated to size of the sinus node or age of the specimen.

Although the sinus node is not encapsulated within connective tissue, in nine hearts $(19 \%)$ from patients aged over 65 years, we observed a layer of connective or fatty tissue between the subendocardium and the body of the node (fig $3 \mathrm{~A}$ ). These represent $56 \%$ of patients older than 65 years.

\section{Topography of the sinus node}

Table 2 shows the minimum and maximum distances between the epicardium, endocardium, and nodal tissue in all hearts. In most hearts $(72 \%)$, the whole nodal body had a subepicardial location of $0.1-1 \mathrm{~mm}$, without intervening atrial working myocardium (fig $1 \mathrm{~A}, \mathrm{~B}$, fig $2 \mathrm{~A}-\mathrm{E}$, fig $3 \mathrm{~A}$ ). The area of the nodal body cranial to the sinus node artery is closer to the endocardium than the nodal portion caudal to this vascular landmark. The nodal tissue caudal to the artery is separated from the endocardium by the thick myocardium of the terminal crest (fig $1 \mathrm{~B}, \mathrm{C}$, fig $2 \mathrm{~A}, \mathrm{~B}, \mathrm{D}, \mathrm{E}$ ). The minimum distance from the most caudal boundaries of the nodal body to the endocardium was $4.2(0.4) \mathrm{mm}$ (range $2.3-4.6 \mathrm{~mm}$ ) and in $50 \%$ of hearts it was $>3.5 \mathrm{~mm}$. In $21(45 \%)$ of our specimens the inner aspect of the entire node was $<3 \mathrm{~mm}$ from the endocardium, and in 13 specimens $(28 \%)$ the body was $<1.5 \mathrm{~mm}$ from the endocardium. When the nodal head was located in the most superior position of the terminal groove ( 10 specimens, $21 \%$ ), it descended obliquely taking a shorter course within the terminal crest to reach the subendocardium. Additionally, when the terminal crest was $>7 \mathrm{~mm}$ thick ( 13 specimens, $28 \%$ ) the tail was subepicardial or intramyocardial in location and separated from the endocardium by a maximum distance 3.9 (0.5) $\mathrm{mm}$ (range $3.3-5.8 \mathrm{~mm})$.

\section{Nodal artery}

The relation of the nodal artery with the head, body, and tail of the sinus node was variable. The body of the node was constantly penetrated by the sinus node artery, which in most specimens (36 hearts, $77 \%$ ) had a central position throughout the length of the node (fig 4). In the remaining instances the artery had an eccentric course alongside the mass of the nodal body. At the nodal head, the artery had an eccentric position in 30 specimens (64\%). In 40 hearts (85\%) the nodal artery penetrated the tail portion eccentrically. In seven of these (18\%), the artery did not reach the most distal portion of the tail but coursed between the tail and the endocardium (fig 4D).

\section{DISCUSSION}

Although early reports described the location and structure of the sinus node, our study provides qualitative and quantitative information that can assist the electrophysiologist in understanding the complexities of mapping and ablating in the area of the sinus node. Despite the lack of electrophysiological and functional data in our series, we emphasise that the sinus node is not insulated from the adjacent atrial myocardium although it consists of densely packed specialised myocytes in a connective tissue matrix and it often surrounds the nodal artery. Located at a variable distance from the endocardium and the terminal crest, it radiates for short distances into the neighbouring atrial myocardium. Thus, the node and its radiations do not fulfil the third criterion of Aschoff ${ }^{19}$ and Mönckeberg ${ }^{20}$ for a specialised tract, namely that it be insulated from the adjacent myocardium. The overall architecture of the node with its radiations and caudal fragment potentially explains the lack of a single breakthrough of the sinus node excitatory wavefront, as well as the difficulties in modifying the node with current techniques for endocardial catheter ablation. 


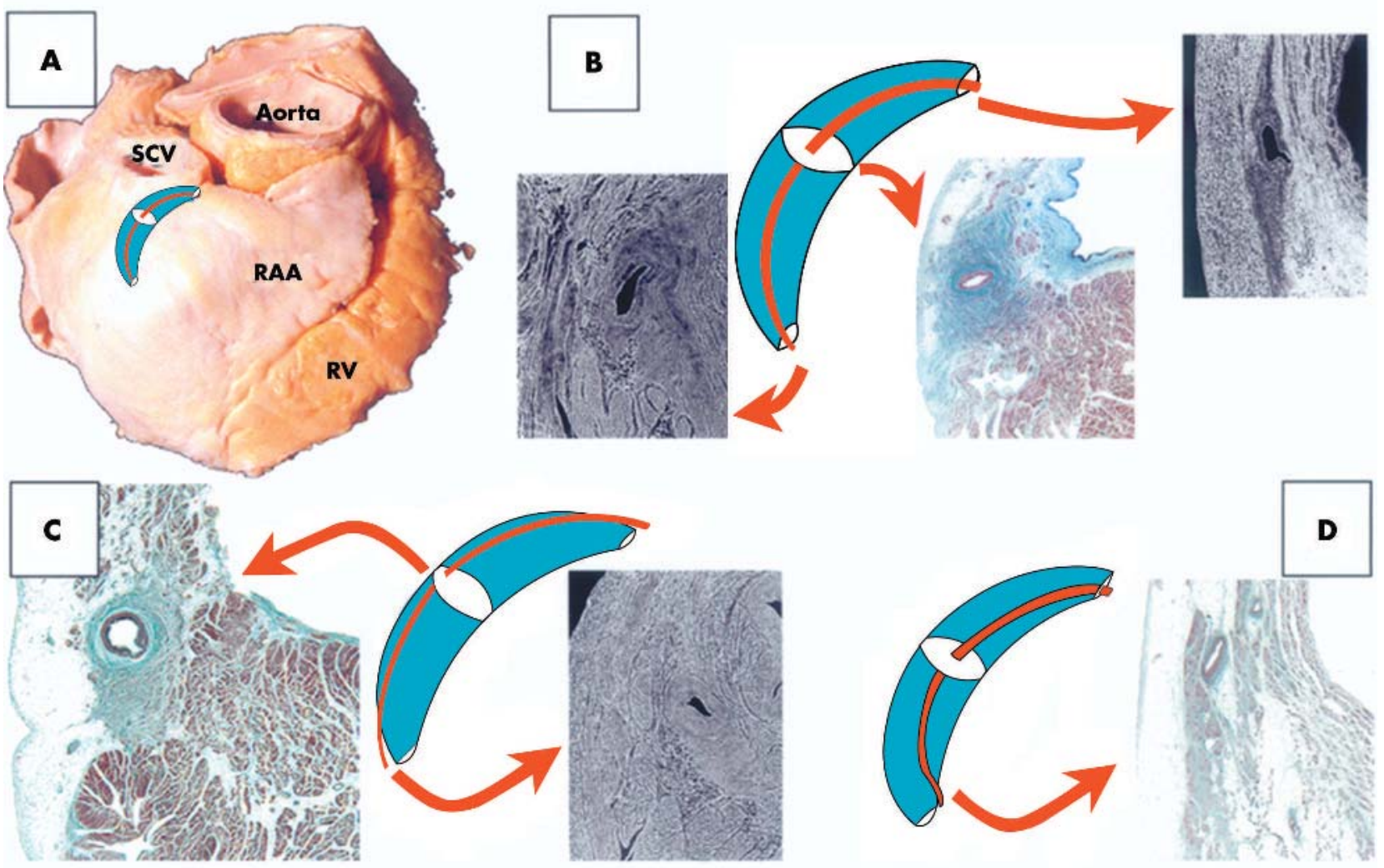

Figure 4 (A) Location of the sinus node (crescent) with a central nodal artery (red line). RAA, right atrial appendage; RV, right ventricle. (B, C, D) Variable relation between the sinus node and its artery. The white ellipses on the node indicate the levels corresponding to the micrographs. (B) Central location of the artery relative to the nodal head, body, and tail. (C) Eccentrically located artery alongside the node. The micrographs show this eccentric location relative to the body and superior to the tail. (D) Instances in which the artery is central in the body but eccentric at the head and the tail. In the tail, the artery passes between the node and the endocardium. Masson trichrome stain.

\section{Communication between sinus node and atrial myocardium}

Three architectural features facilitate communication between the sinus node and right atrial myocardium. These are the lack of insulation of the specialised nodal tissue, the sickle shaped morphology of the node with an extensive longitudinal axis, and the radiations from the node into the neighbouring myocardium.

Intraoperative epicardial mapping studies of the human heart have shown that the sinus nodal pacemaker occupies a large anatomical area. $^{69}$ The use of a non-fluoroscopic computerised system to provide global electroanatomical activation mapping of the sinus node has been shown to be effective in guiding ablation for IST. ${ }^{5}$ In future, the combination of this type of mapping system with high resolution computed tomography or three dimensional magnetic resonance imaging will allow even more precise localisation of the anatomical structures. The nodal length in our study was $8-21.5 \mathrm{~mm}$, being $>16 \mathrm{~mm}$ in $50 \%$ of the hearts, a figure that accords well with previous electrophysiological observations.

In $74 \%$ of our specimens, we found $1-10$ radiations from the sinus node into the atrial wall, thus confirming the observation of Chuaqui, ${ }^{21}$ which is scarcely mentioned in other studies. We encountered nodal radiations, $0.2-2 \mathrm{~mm}$ long, which extended superiorly towards the superior caval vein, inferiorly towards the subepicardium, and intramurally into the ordinary myocardium of the terminal crest or intercaval area. The radiations of the node were histologically discrete and they too were not insulated from the remaining atrial myocardium. Furthermore, we found no insulated bundles extending out of the node and running as tracts through the adjacent atrial myocardium in a manner comparable with the ventricular conduction pathways. These findings, together with the non-compact arrangement of the nodal tail in many cases, may account for the absence of a single discrete site of exit of the sinus node activation front into the right atrium. ${ }^{4}{ }^{6}$

\section{Implications for ablating or modifying the sinus node in patients with IST}

It has been shown that the region of the node can produce sinus tachycardia in the majority of patients. Total ablation of the node from the superolateral aspect of the terminal crest to its distal third produces an unacceptably high requirement for permanent implantation of pacemakers. On the other hand, modification of the node by direct radiofrequency application that is limited to the superolateral aspect of the terminal crest achieves a satisfactory heart rate by preserving part of the sinus node and, consequently, better long term physiological function. Marrouche and colleagues ${ }^{5}$ emphasised that sinus node modification is more than a focal ablation. Instead, it requires complete abolition of the cranial portion of the node. They cited a mean ablation area of 129 (4) $\mathrm{mm}$ by 19 (5) $\mathrm{mm}$. In their series, temporary or permanent sinus arrest, or complete sinoatrial block, did 
not occur in any of their 39 patients with IST subjected to electroanatomical guided catheter ablation, including the 12 patients in whom an $8 \mathrm{~mm}$ electrode tip or an irrigated tip catheter was used. ${ }^{5}$ Our anatomical findings offer three architectural features as probable explanations for the presumed resilience of the node to endocardial catheter ablation: the dense matrix of connective tissue in which the specialised sinoatrial cells are packed; the cooling effect of the nodal artery; and the thick terminal crest, particularly in relation to the nodal portion caudal to the sinus node artery.

Little is known about the protective effects of connective tissue on myocardium. Radiofrequency current produces resistive heating of a thin rim of myocardial tissue $(<1 \mathrm{~mm})$ in direct contact with the ablating electrode. ${ }^{22}$ Connective tissue seems to be more resistant to radiofrequency heating than the myocardium. ${ }^{23}$ Although myocardial bundles can be irreversibly damaged when tissue is heated to $50^{\circ} \mathrm{C}$, denaturation of collagen may require temperatures above $60^{\circ} \mathrm{C} .^{23}$

Fuller and Wood $^{24}$ have shown that intramural arterial branches protect the surrounding myocardium in direct relation to the rate of arterial flow and the intramural arterial diameter. A centrally located nodal artery may preserve a cuff of nodal tissue along the length of the vessel. The variable relation of the artery may account for the variable results of sinus node modification with endocardial ablation techniques in patients with IST..$^{3-5}$

Often, owing to the thickness of the terminal crest, a large mass of the nodal tissue can be relatively distant from the endocardium. In $50 \%$ of our specimens, the distance from the most caudal boundaries of the nodal body to the endocardium was $>3.5 \mathrm{~mm}$. Overall, the maximum distance of 4.8 (0.5) $\mathrm{mm}$ (range 3.3-5.3 mm) suggests that this part of the node is more likely to be preserved after application of radiofrequency energy to the endocardial surface. This may explain the clinical observation that radiofrequency ablation in patients with IST results in a caudal shift of the right atrial endocardial breakthrough of the sinoatrial pacemaking wavefront. ${ }^{35}$ If the node is completely destroyed, another explanation may be provided by the appearance of a subsidiary pacemaker that may be vested in the fragments of the nodal tail or other atrial tissues.

\section{Sinus nodal architecture and sinus nodal re-entry}

Our observations suggest that the architecture of the sinus node potentially can provide an inherent substrate for SNRT. The presence of the dense matrix of connective tissue separating the nodal cells may facilitate slow conduction by increasing the uncoupling of intercellular transmission. ${ }^{25} 26$ The latter feature, combined with multiple potential sites of entry and exit for an excitatory wavefront due to the lack of an insulating connective tissue sheath, and the presence of nodal radiations interweaving with the working atrial myocardium, make an ideal substrate for re-entry, albeit a hypothesis that is outside the scope of this study.

In conclusion, although our anatomical study is without functional or electrophysiological correlates, we have provided details relevant to electroanatomical mapping and catheter ablation or modification of the sinus node. The question remains, of course, as to whether the anatomy shown is sufficient to set the scene for developing treatments for IST.

\section{ACKNOWLEDGEMENTS}

We thank Professors Duarte Nuno-Vieira and Maria Cristina de Mendonça, Instituto Nacional de Medicina Legal (Coimbra), Portugal, for allowing us to examine specimens in this series.
Sources of funding: grant 02/0039 from Junta de Extremadura (DSQ and VC), and Royal Brompton and Harefield Hospital Charitable Fund (SYH).

\section{Authors' affiliations}

D Sánchez-Quintana, V Climent, Departamento de Anatomía Humana, Facultad de Medicina, Universidad de Extremadura, Badajoz, Spain

J A Cabrera, J Farré, Servicio de Cardiología, Fundación Jiménez Díaz, Universidad Autónoma, Madrid, Spain

R H Anderson, Cardiac Unit, Institute of Child Health, University College, London, UK

S Y Ho, National Heart and Lung Institute, Imperial College, and Royal Brompton and Harefield Hospitals, London, UK

Presented in part at the 75th Scientific Sessions of the American Heart Association. Chicago, Illinois, 17-20 November 2002

\section{REFERENCES}

1 Morillo CA, Klein GJ, Thakur RK, et al. Mechanism of 'inappropriate' sinus tachycardia: role of sympathovagal balance. Circulation 1994;90:873-7.

2 Chen SA, Chiang CE, Yang CJ, et al. Radiofrequency catheter ablation of sustained intra-atrial re-entrant tachycardia in adult patients: identification of electrophysiological characteristics and endocardial mapping techniques. Circulation 1993;88:578-87.

3 Man KC, Knight B, Tse HF, et al. Radiofrequency catheter ablation of inappropriate sinus tachycardia guided by activation mapping. J Am Coll Cardiol 2000;35:451-7.

4 Lee RJ, Kalman JM, Fitzpatrick AP, et al. Radiofrequency catheter modification of the sinus node for "inappropriate" sinus tachycardia. Circulation 1995;92:2919-28.

5 Marrouche NF, Beheiry S, Tomassoni G, et al. Three-dimensional nonfluoroscopic mapping and ablation of inappropriate sinus tachycardia. J Am Coll Cardiol 2002;39:1045-54.

6 Boineau JP, Schuessler RB, Mooney CR, et al. Multicentric origin of the atrial depolarization wave: the pacemaker complex. Circulation 1978;58:1036-48.

7 Boineau JP, Schuessler RB, Hackel DB, et al. Widespread distribution and rate differentiation of the atrial pacemaker complex. Am J Physiol 1980;239:H406-15.

8 Boineau JP, Canavan TE, Schuessler RB, et al. Demonstration of a widely distributed atrial pacemaker complex in the human heart. Circulation 1988;77:1221-37.

9 Schuessler RB, Boineau JP, Bromberg BI. Origin of the sinus impulse. J Cardiovasc Electrophysiol 1996;7:263-74.

10 De Ponti R, Ho SY, Salerno-Uriarte JA, et al. Electroanatomic analysis of sinus impulse propagation in normal human atria. J Cardiovasc Electrophysiol 2002;13:1-10.

11 Ren JF, Marchlinski FE, Callans DJ, et al. Echocardiographic lesion characteristics associated with successful ablation of inappropriate sinus tachycardia. J Cardiovasc Electrophysiol 2001;12:814-8.

12 Keith A, Flack $M$. The form and nature of the muscular connections between the primary divisions of the vertebrate heart. J Anat Physiol 1907;41:172-89.

13 James TN. Anatomy of the human sinus node. Anat Rec 1961;141:109-16.

14 Ryback R, Mizeres NJ. The sinus node artery in man. Anat Rec 1965;153:23-30.

15 Truex RC, Smythe MQ, Taylor MJ. Reconstruction of the human sinoatrial node. Anat $\operatorname{Rec} 1967 ; 159: 371-8$.

16 Anderson KR, Ho SY, Anderson RH. Location and vascular supply of sinus node in human heart. Br Heart J 1979:41:28-32.

17 Chiu I, Hung CR, How SW, et al. Is the sinus node visible grossly? A histological study of normal hearts. Int J Cardiol 1989;22:83-7.

$18 \mathrm{He}$ B, Tan Y, Cheng M, et al. The surgical anatomy of the sinoatrial node. Surg Radiol Anat 1991;13:123-8.

19 Aschoff L. Referat über die Herzstörungen in ihren Bezienhungen zu den spezifischen Muskelsystemen des Herzens. Ver Dtsch Pathol Ges 1910;14:3-35.

20 Mönckeberg JG. Zur Entwicklungsgeschichte des Atrioventrikularsystems. Ver Dtsch Pathol Ges 1913;16:228-49.

21 Chuaqui B. Lupenpräparatorische Darstellung der Ausbreitungszüge des Sinusknotens. Virchows Arch Abt A Pathol Anat 1972;356:141-53.

22 Haines DE. The biophysics of radiofrequency catheter ablation in the heart: the importance of temperature monitoring. Pacing Clin Electrophysiol 1993; 16:586-91.

23 Kok LC, Everett TH 4th, Akar JG, et al. Effect of heating on pulmonary veins: how to avoid pulmonary vein stenosis. J Cardiovasc Electrophysiol 2003;14:250-4.

24 Fuller IA, Wood MA. Intramural coronary vasculature prevents transmural radiofrequency lesion formation: implications for linear ablation. Circulation 2003; 107:1797-803

25 Spach MS, Dolber PC, Heidlage JF. Interaction of inhomogeneities of repolarization with anisotropic propagation in dog atria: a mechanism for both preventing and initiating reentry. Circ Res 1989;48:39-54.

26 Spach MS, Josephson ME. Initiating reentry: the role of nonuniform anisotropy in small reentry circuits. J Cardiovasc Electrophysiol 1994;5:182-209. 